\section{Case Reports in Gastroenterology}

Case Rep Gastroenterol 2017;11:312-319

DOI: $10.1159 / 000475919$

Publisned on Ine: VIay 19, 2017 (c) 2017 The Author(s)

Published by S. Karger AG, Basel www.karger.com/crg

This article is licensed under the Creative Commons Attribution-NonCommercial 4.0 International License (CC BY-NC) (http://www.karger.com/Services/OpenAccessLicense). Usage and distribution for commercial purposes requires written permission.

\title{
Kidney Injury due to Ureteral Obstruction Caused by Compression from Infected Simple Hepatic Cyst
}

\author{
Naoya Sawada ${ }^{a}$ Tetsu Endo ${ }^{a}$ Kenichiro Mikami ${ }^{a}$ Go Igarashi ${ }^{a}$ \\ Juichi Sakamoto $^{b}$ Hiroshi Tono $^{b}$ Shinsaku Fukuda ${ }^{a}$ \\ ${ }^{a}$ Department of Gastroenterology and Hematology, Hirosaki University Graduate School \\ of Medicine, Hirosaki, Japan; ${ }^{\mathrm{b}}$ Department of Internal Medicine, Hirosaki Municipal \\ Hospital, Hirosaki, Japan
}

\section{Keywords}

Simple hepatic cysts - Ureteral obstruction - Ultrasound-guided percutaneous drainage .

Sclerotherapy · Minocycline hydrochloride

\section{Abstract}

Simple hepatic cysts are common and most often asymptomatic. In symptomatic cases, hemorrhage, rupture, and infection are major complications. However, urinary tract obstruction caused by a simple hepatic cyst is rare. We treated an 82-year-old Japanese man with an infected giant hepatic cyst causing right hydronephrosis who had a past history of left nephrectomy for renal cell carcinoma. The patient underwent ultrasound-guided percutaneous drainage and sclerotherapy with minocycline hydrochloride for the infected hepatic cyst. Right hydronephrosis was relieved, and renal dysfunction improved with regression of the hepatic cyst after treatment. This is the first report of hydronephrosis due to ureteral obstruction caused by compression from a hepatic cyst. 


\section{Case Reports in Gastroenterology}

\section{Introduction}

Simple hepatic cysts are common and benign lesions. They are usually asymptomatic and have no effect on liver function, and are diagnosed based on incidental findings on abdominal imaging such as ultrasonography (US) and computed tomography (CT). However, they cause symptoms when they are complicated by infection, rupture, intracystic hemorrhage, obstructive jaundice, and/or compression of vascular systems [1-3].

However, ureteral obstruction due to compression from a benign lesion of the liver is very rare [4]. We describe the case of a patient with an infected giant hepatic cyst that obstructed the ureteral tract, who was successfully treated with cystic drainage and sclerotherapy.

\section{Case Report}

An 82-year-old man presented to his general practitioner with anorexia, abdominal distension, pain, and fever. His past medical history consisted of left nephrectomy for renal cell carcinoma at 66 years of age. He had been found to have simple hepatic cysts at 55 years of age, and received a follow-up examination from his general practitioner with CT. Plain CT scanning and US revealed enlargement of a simple hepatic cyst measuring $20 \mathrm{~cm}$ in diameter, right hydronephrosis, and gallstones in the compressed gallbladder (Fig. 1). Laboratory analysis showed severe inflammation and renal dysfunction. Thus, he was referred and admitted to our hospital for further evaluation and treatment. Laboratory data on admission showed increased serum C-reactive protein (CRP) and creatinine levels: 34.0 and 1.61 $\mathrm{mg} / \mathrm{dL}$, respectively (Table 1). Liver function tests and serum tumor marker levels were within the normal range, except for a slight elevation in alkaline phosphatase (385 IU/L, reference range: 115-359). Urinalysis showed no signs of urinary tract infection, and blood culture was negative. Although CT showed gallstones, acute cholecystitis was negative due to almost normal liver function tests. Therefore, we diagnosed the patient with an infected hepatic cyst complicated by urinary tract obstruction, and we prescribed intravenous drip infusion of cefoperazone sodium and sulbactam sodium ( $1 \mathrm{~g}$, twice a day). Despite intravenous drip infusion of antibiotics, the patient's fever persisted. Thus, we inserted a drainage tube into the largest hepatic cyst with suspected infection under ultrasound guidance. About $3,800 \mathrm{~mL}$ of yellow, turbid fluid was drained. Cystography did not show any communication between the intrahepatic bile ducts. Then, $400 \mathrm{mg}$ of minocycline hydrochloride in $40 \mathrm{~mL}$ of saline was injected for conglutination. The catheter was clamped and reopened after $24 \mathrm{~h}$. Streptococcus parasanguinis was isolated from the cyst fluid. Cystic fluid carbohydrate antigen 19-9 (CA19-9) level was 264,338 U/mL (normal range for serum CA19-9 level: 0-35). However, neoplastic cells were not detected in the cystic fluid. We injected minocycline hydrochloride 2 more times, on days 4 and 12, after catheter insertion. After drainage, abdominal symptoms and fever resolved, and serum CRP and creatinine levels improved (Fig. 2). The amount of daily drainage gradually decreased from approximately $1,000 \mathrm{~mL}$ to about $100 \mathrm{~mL}$. Follow-up CT scan and abdominal US showed prominent regression of the hepatic cyst and relief of the ureteral obstruction (Fig. 3). Thus, we removed the catheter 19 days after insertion. Regarding his gallstones, magnetic resonance cholangiopancreatography 
Sawada et al.: Kidney Injury due to Ureteral Obstruction Caused by Compression from Infected Simple Hepatic Cyst

(MRCP) also revealed a common bile duct stone. Thus, we treated him by endoscopic retrograde cholangiopancreatography (ERCP), sphincterotomy, and stone removal. ERCP did not show any communication between the intrahepatic bile ducts. His asymptomatic gallstones were followed up without cholecystectomy due to his age. The patient was then discharged in excellent general condition 1 month after admission. He has since shown an uneventful course without reenlargement of the hepatic cyst.

\section{Discussion}

Simple hepatic cysts are most often asymptomatic and are increasingly being diagnosed because of improved imaging techniques. They are estimated to have a prevalence of 2.5$4.7 \%$ in the general population and $11.3 \%$ in patients referred to a hospital, with increasing frequency with advancing age $[5,6]$. Infection of hepatic cysts occurs in 1-3\% of patients with polycystic liver disease and autosomal dominant polycystic kidney disease [7]. Bacterial organisms can invade a hepatic cyst through the bile ducts or a hematogenous route [8]. In terms of microbiological findings, $77 \%$ of patients with an infected hepatic cyst show positive cyst aspiration culture, with Escherichia coli being the most common isolated pathogen [9]. Besides E. coli, Klebsiella pneumonia, Enterococcus faecium, Enterobacter cloacae, Pseudomonas aeruginosa, Haemophilus parainfluenzae, and others have been isolated from cyst aspiration culture in patients with an infected hepatic cyst [9]. In our case, a culture of cystic fluid was positive for $S$. parasanguinis, which presumably came from a hematogenous route, because $S$. parasanguinis is an indigenous bacterium in the oral cavity, and there was no communication between the intrahepatic bile ducts despite bearing a common bile duct stone.

Cystic fluid CA19-9 levels were markedly elevated in our patient, while serum CA19-9 levels were within the normal range. Cystic fluid CA19-9 may be produced from a biliarytype epithelium that covers the cystic lumen [10]. Serum and cyst fluid CA19-9 levels are elevated in patients not only with cystadenocarcinoma but also with infected hepatic cysts $[10,11]$. In our patient, there was no nodular lesion in the cyst, and cytology of the cystic fluid was negative; thus, we concluded that cystadenocarcinoma was unlikely.

Management of symptomatic hepatic cysts consists of surgery or percutaneous treatment [12]. In terms of surgical treatment, cyst deroofing, cystectomy, cystoenterostomy, and liver resection have been performed [13]. As for percutaneous treatment, ultrasound-guided percutaneous drainage followed by administration of a sclerosing agent such as ethanol, minocycline hydrochloride, or monoethanolamine oleate has been successful with minimal invasion, and the recurrence rate is low [14].

Ureteral obstruction can result from mechanical blockade or functional defects, and it can cause hydronephrosis leading to impairment of renal function. Therefore, it is important to resolve hydronephrosis promptly. In our case, in particular, the patient had only the right kidney due to his history of left nephrectomy for renal cell carcinoma; thus, it was absolutely necessary to maintain his renal function by relieving the hydronephrosis. Mechanical causes of ureteral obstruction are congenital, acquired intrinsic defect, and acquired extrinsic defect. In adults, ureteral obstruction is due mainly to acquired defects such as a tumor, calculi, or inflammation. Various acquired extrinsic defects have been reported such as pregnant 
Sawada et al.: Kidney Injury due to Ureteral Obstruction Caused by Compression from Infected Simple Hepatic Cyst

uterus, retroperitoneal fibrosis, aortic aneurysm, and carcinoma of the uterus, prostate, or colon [15]. To our knowledge, however, there have been no reports of ureteral obstruction due to a hepatic cyst in the literature. There is one report of hydronephrosis due to a giant hemangioma of the liver [4]. In our case, the presence of hepatic cysts was known for 27 years, but infection might rapidly increase the size of a hepatic cyst following ureteral compression.

In conclusion, we have reported a case of an infected simple hepatic cyst causing urinary tract obstruction leading to hydronephrosis that resolved by ultrasound-guided percutaneous drainage and sclerotherapy with minocycline hydrochloride. Although ureteral obstruction due to compression with a hepatic cyst is very rare, the mass effect of an enlarged hepatic cyst should be considered as a possible cause of hydronephrosis, and it should be promptly treated with drainage to relieve urinary tract compression.

\section{Statement of Ethics}

The authors have no ethical conflicts to disclose.

\section{Disclosure Statement}

The authors declare no conflicts of interest for this article.

\section{References}

1 Musielak MC, Singh R, Hartman E, Bernstein J: Simple hepatic cyst causing inferior vena cava thrombus. Int J Surg Case Rep 2014;5:339-341.

-2 Miyamoto M, Oka M, Izumiya T, Nagaoka T, Ishihara Y, Ueda K, Enomoto S, Yanaoka K, Arii K, Tamai H, Shimizu Y, Ichinose M: Nonparasitic solitary giant hepatic cyst causing obstructive jaundice was successfully treated with monoethanolamine oleate. Intern Med 2006;45:621-625.

-3 Miliadis L, Giannakopoulos T, Boutsikos G, Terzis I, Kyriazanos ID: Spontaneous rupture of a large nonparasitic liver cyst: a case report. J Med Case Rep 2010;4:2.

4 Aguilar A, Pozuelo 0, Castells M, Vargas C: Hydronephrosis: a rare complication of hepatic haemangiomas. BJU Int 2002;90:621.

5 Caremani M, Vincenti A, Benci A, Sassoli S, Tacconi D: Ecographic epidemiology of non-parasitic hepatic cysts. J Clin Ultrasound 1993;21:115-118.

6 Caremani M, Vincenti A, Benci A, Sassoli S, Tacconi D: The occurrence of asymptomatic and symptomatic simple hepatic cysts. A prospective, hospital-based study. Clin Radiol 2005;60:10261029.

7 Grunfeld JP, Albouze G, Jungers P, Landais P, Dana A, Droz D, Moynot A, Lafforgue B, Boursztyn E, Franco D: Liver changes and complications in adult polycystic kidney disease. Adv Nephrol Necker Hosp 1985;14:1-20.

8 Yoshida H, Onda M, Tajiri T, Mamada Y, Taniai N, Mineta S, Hirakata A, Futami R, Arima Y, Inoue M, Hatta S, Kishimoto A: Infected hepatic cyst. Hepatogastroenterology 2003;50:507-509.

-9 Lantinga MA, Drenth JP, Gevers TJ: Diagnostic criteria in renal and hepatic cyst infection. Nephrol Dial Transplant 2015;30:744-751.

10 Wijnands TF, Lantinga MA, Drenth JP: Hepatic cyst infection following aspiration sclerotherapy: a case series. J Gastrointestin Liver Dis 2014;23:441-444. 
11 Yanai H, Tada N: A simple hepatic cyst with elevated serum and cyst fluid CA19-9 levels: a case report. J Med Case Rep 2008;2:329.

12 Mazza OM, Fernandez DL, Pekolj J, Pfaffen G, Sanchez Claria R, Molmenti EP, de Santibanes E: Management of nonparasitic hepatic cysts. J Am Coll Surg 2009;209:733-739.

13 Garcea G, Rajesh A, Dennison AR: Surgical management of cystic lesions in the liver. ANZ J Surg 2013;83:516-522.

14 Blonski WC, Campbell MS, Faust T, Metz DC: Successful aspiration and ethanol sclerosis of a large, symptomatic, simple liver cyst: case presentation and review of the literature. World J Gastroenterol 2006;12:2949-2954.

15 Seifter JL: Urinary tract obstruction; in Kasper DL, Fauci AS, Hauser SL (eds): Harrison's Principles of Internal Medicine, ed 19. New York, McGraw-Hill, 2015, pp 1871-1874.
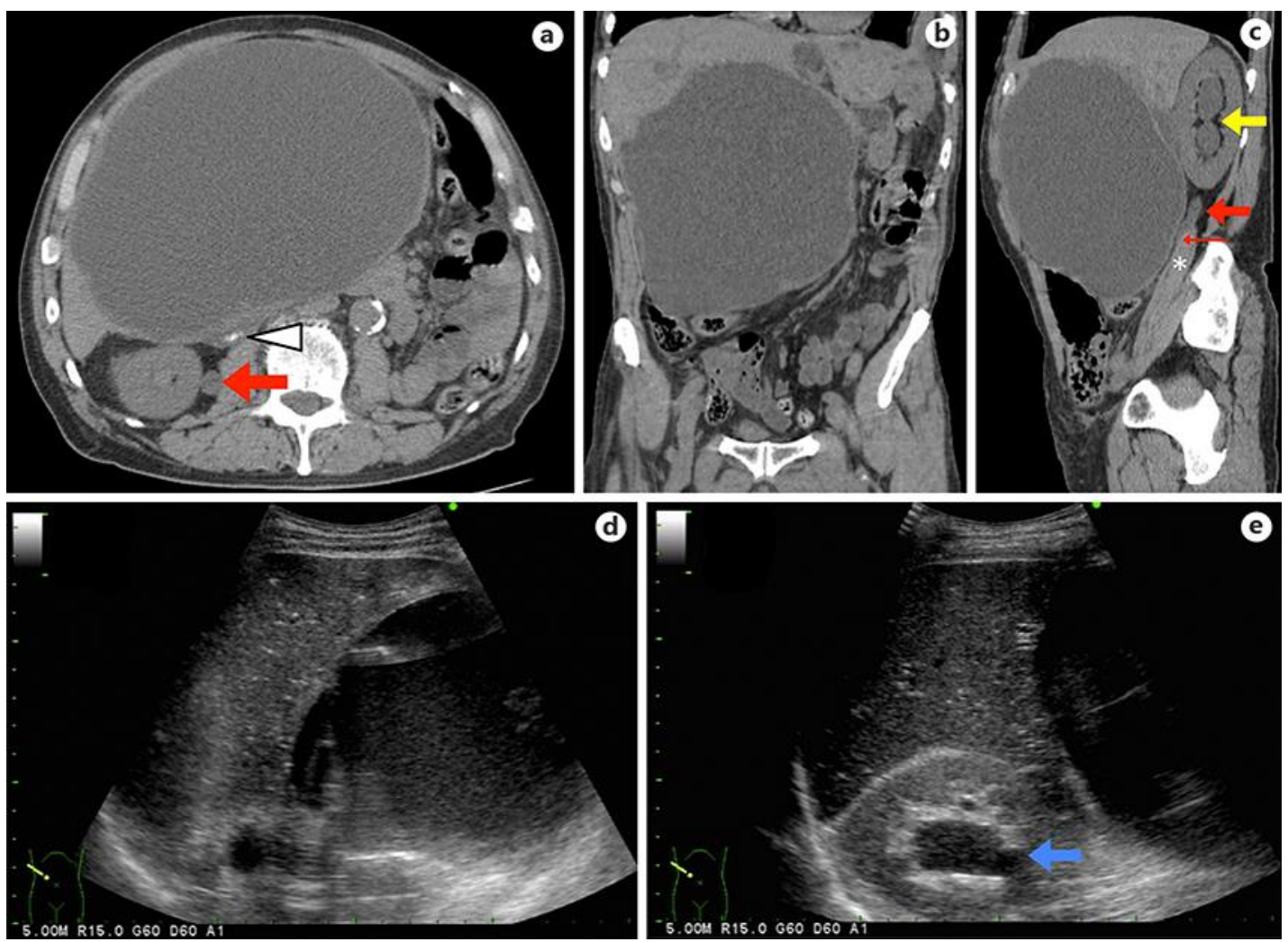

Fig. 1. Plain CT transverse (a), coronal (b), and sagittal (c) sections showing a 20-cm cystic lesion in the right lobe of the liver and dilatation of the right pelvis (yellow arrow) and proximal ureter (red arrow) due to compression of the ureter (thin red arrow) wedged between the hepatic cyst and iliopsoas muscle (asterisk). Gallstones were indicated in the compressed gallbladder (arrowhead). Abdominal US showed a large cystic lesion with homogeneous contents without a septum or calcifications (d), and the right kidney with hydronephrosis (blue arrow) (e). 
Sawada et al.: Kidney Injury due to Ureteral Obstruction Caused by Compression from Infected Simple Hepatic Cyst

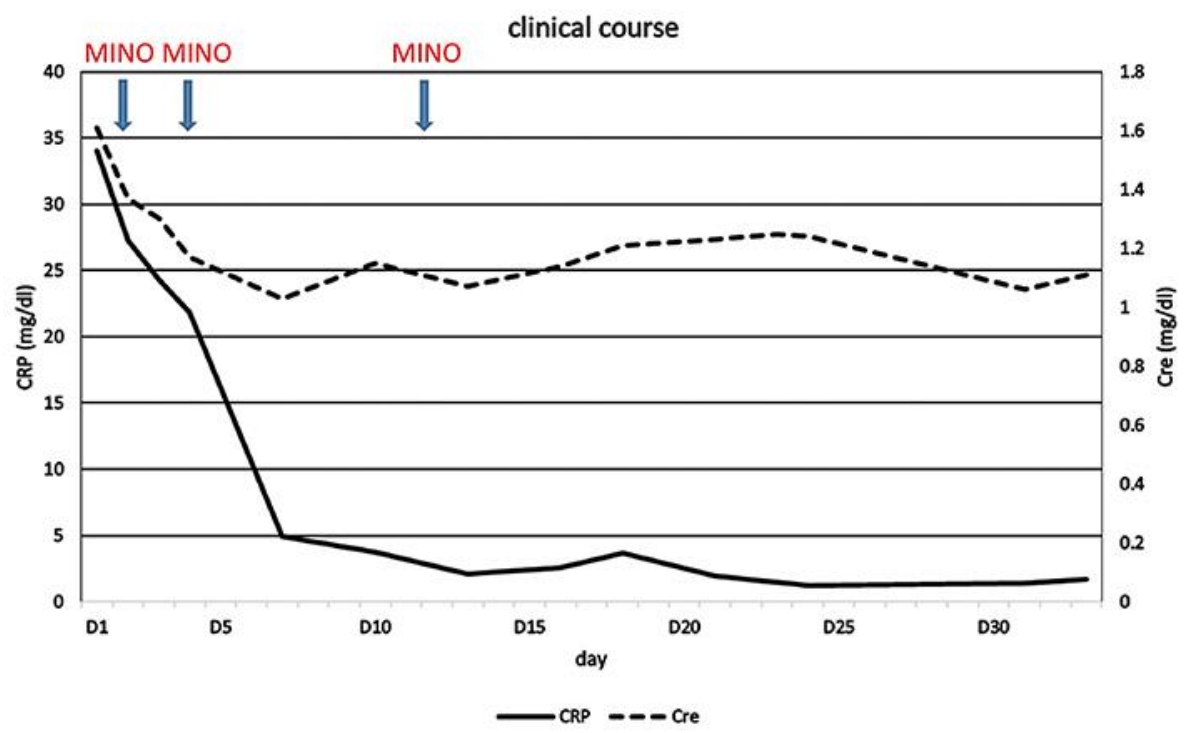

Fig. 2. Changes in the levels of serum CRP and creatinine during the clinical course. CRP, C-reactive protein; Cre, creatinine; MINO, minocycline hydrochloride. After drainage, serum CRP and creatinine levels improved. 


\begin{tabular}{ll|l} 
Case Reports in & \begin{tabular}{l} 
Case Rep Gastroenterol 2017;11:312-319 \\
\cline { 2 - 3 } Gastroenterology
\end{tabular} & $\begin{array}{l}\text { D } 10.1159 / 000475919 \\
\text { www.karger.com/crg }\end{array}$ \\
\cline { 2 - 2 } & $\begin{array}{l}\text { Sawada et al.: Kidney Injury due to Ureteral Obstruction Caused by Compression from } \\
\text { Infected Simple Hepatic Cyst }\end{array}$
\end{tabular}
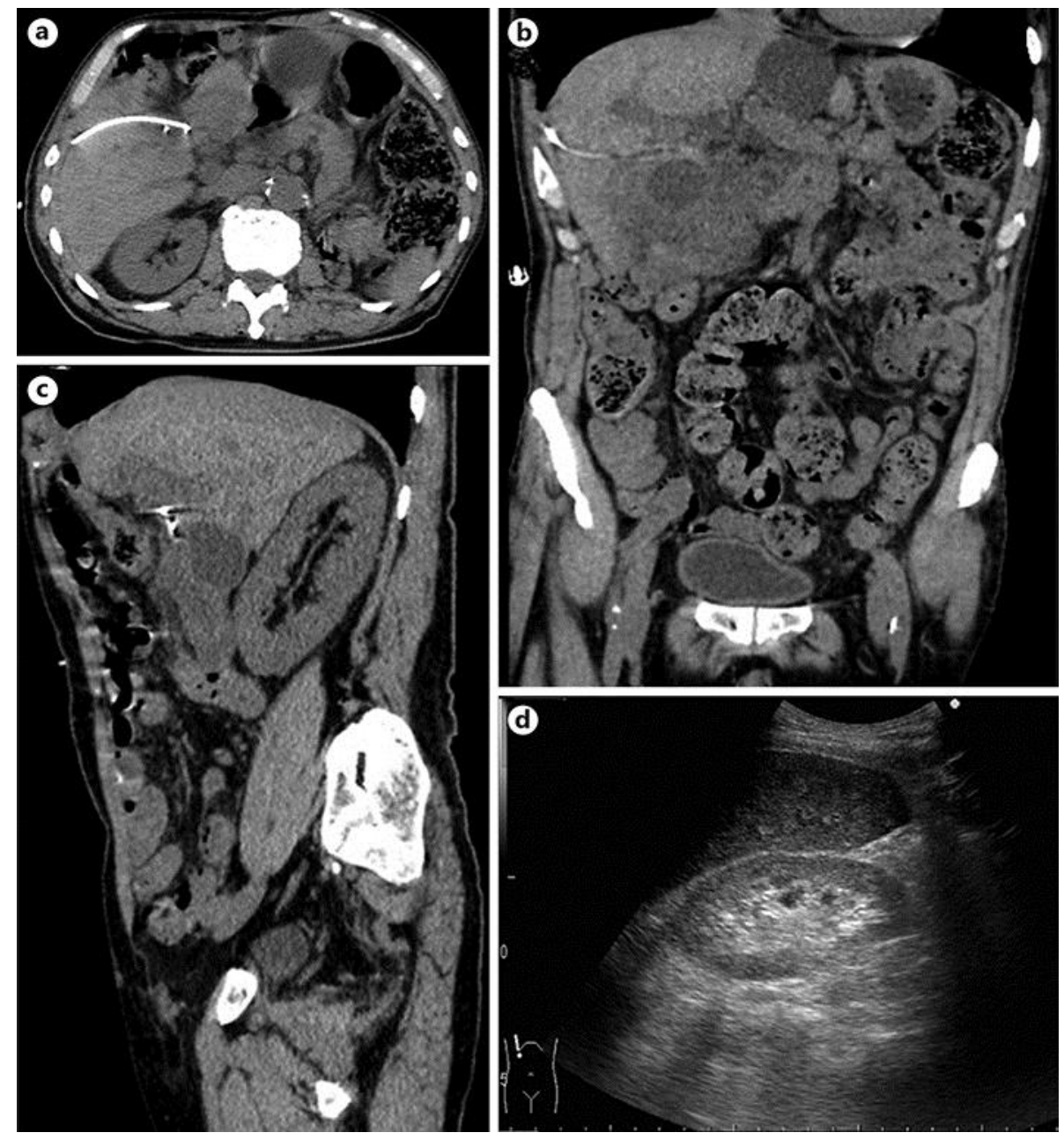

Fig. 3. CT performed 18 days after catheter insertion showed marked regression of the hepatic cyst (a, b) and relief of the ureteral obstruction (c). d Abdominal US showed relief of right hydronephrosis. 
Sawada et al.: Kidney Injury due to Ureteral Obstruction Caused by Compression from Infected Simple Hepatic Cyst

Table 1. Laboratory data on admission

\begin{tabular}{|c|c|c|}
\hline & Value & $\begin{array}{l}\text { Reference } \\
\text { range }\end{array}$ \\
\hline White blood cell count, $/ \mu \mathrm{L}$ & 5,490 & $3,500-8,500$ \\
\hline Hemoglobin, g/dL & 12.1 & $13.5-17.0$ \\
\hline Platelet count, $10^{4} / \mu \mathrm{L}$ & 20.6 & $15.0-35.0$ \\
\hline Total protein, g/dL & 6.6 & $6.7-8.3$ \\
\hline Albumin, g/dL & 2.9 & $3.5-5.5$ \\
\hline Blood urea nitrogen, mg/dL & 31 & $8-22$ \\
\hline Creatinine, mg/dL & 1.61 & $0.6-1.1$ \\
\hline Sodium, mmol/L & 136 & $138-146$ \\
\hline Potassium, mmol/L & 3.6 & $3.6-4.9$ \\
\hline Chloride, mmol/L & 100 & $99-100$ \\
\hline Calcium, mg/dL & 8.6 & $8.7-10.3$ \\
\hline Glucose, mg/dL & 112 & $70-109$ \\
\hline Aspartate aminotransferase, U/L & 29 & $13-33$ \\
\hline Alanine aminotransferase, $\mathrm{U} / \mathrm{L}$ & 30 & $8-42$ \\
\hline Alkaline phosphatase, $\mathrm{U} / \mathrm{L}$ & 385 & $115-359$ \\
\hline Lactate dehydrogenase, U/L & 143 & $119-229$ \\
\hline Total bilirubin, mg/dL & 1.0 & $0.3-1.2$ \\
\hline$\gamma$-Glutamyltranspeptidase, $\mathrm{U} / \mathrm{L}$ & 32 & $10-47$ \\
\hline Choline esterase, $\mathrm{U} / \mathrm{L}$ & 122 & $168-470$ \\
\hline Creatine kinase, U/L & 31 & $62-287$ \\
\hline Amylase, U/L & 40 & $37-125$ \\
\hline C-reactive protein, $\mathrm{mg} / \mathrm{dL}$ & 34.055 & $0.000-0.300$ \\
\hline Prothrombin time, $\%$ & 60 & $70-120$ \\
\hline International normalized ratio & 1.34 & \\
\hline Activated partial thromboplastin time, s & 51.7 & $26.0-36.0$ \\
\hline Fibrinogen, mg/dL & 934 & $150-450$ \\
\hline $\mathrm{FDP}, \mu \mathrm{g} / \mathrm{mL}$ & 11.8 & $0.0-5.0$ \\
\hline D-dimer, $\mu \mathrm{g} / \mathrm{mL}$ & 1.8 & $0.0-0.4$ \\
\hline CA19-9, U/mL & 35 & $0-35$ \\
\hline
\end{tabular}

FDP, fibrin and fibrinogen degradation products. 